\title{
LA FRONTERA COMO ZONA DE CONTACTO TRANSNACIONAL EN LA LITERATURA LATINA ESTADOUNIDENSE
}

\author{
Macarena GARCÍA-A VELLO
}

Universidad de Cantabria

$\mathrm{E}$ n su ensayo "The Politics of Literature" Rancière niega que exista una oposición nítida entre actuar y escribir, ya que a través de la literatura se lleva a cabo una partición de lo sensible que interviene sobre la realidad, visibilizando y nombrando ciertos aspectos de la misma. En palabras de Rancière, "the symptomatic reading that underpins the practices of historical or sociological interpretation was first of all a poetical revolution" (2004: 21). El poder de la literatura de desestabilizar la jerarquía de lo que es representable la vincula, por consiguiente, a la política. Dentro del campo de U. S. Latina/o se pueden identificar una serie de novelas que ilustran magníficamente esta tesis, pues ofrecen una narrativa inseparable de la producción de epistemología que las conecta a la práctica del "theory in the flesh" (1981: 23) propuesta por Cherrie Moraga y Gloria Anzaldúa en This Bridge Called my Back. En este trabajo se analizarán las siguientes obras en relación con la teoría propuesta por Gloria Anzaldúa en Borderlands/La Frontera: The New Mestiza (1987) con el fin de explorar la construcción de subjetividades fronterizas por medio de textos híbridos que producen una epistemología inseparable de lo político. The House on Mango Street (1984) de Sandra Cisneros, How the Garcia Girls Lost their Accent (1991) y Yo (1997) de Julia Álvarez, Dreaming in Cuban (1992) de Cristina García, Desert Blood: The Juarez Muerders (2005) de Alicia Gaspar de Alba y Las historias prohibidas de Marta Veneranda (1997) de Sonia Rivera-Valdés. Todos estos textos reflexionan acerca del papel de la escritura, o de la creación artística en el caso de Dreaming in Cuban, a la hora de configurar las subjetividades mediante las que estructurar, interpretar y otorgar significado a los proyectos vitales, poéticos y políticos de las protagonistas.

Este trabajo propone relacionar autoras canónicas dentro de la literatura latina con otras menos conocidas, como Rivera-Valdés o Gaspar de Alba. Si bien es cierto que Cisneros, Álvarez o García han recibido gran atención por parte de la crítica, conviene revisar estos textos desde una perspectiva transnacional que permita establecer un diálogo entre distintas obras pertenecientes a contextos diversos. Concretamente, se analizarán estas obras a la luz de la epistemología subyacente a Borderlands/La frontera. Aunque Anzaldúa se centra en un contexto muy concreto -el de la lucha política en la frontera entre Estados Unidos y México-, el modelo teórico que plantea en torno a 
experiencias psicológicas, espirituales y sexuales de la frontera entendida como metáfora puede relacionarse con la epistemología proyectada en las obras seleccionadas. Mi análisis parte de la tesis de que la idea de "la frontera" no se limita al contexto chicano, sino que proporciona una categoría de análisis muy útil a la hora de aproximarse a ciertas escritoras latinas de distintos orígenes y grupos sociales. Por lo tanto, la frontera se concibe como espacio transnacional que posibilita una zona de contacto en la que diferentes voces latinas articulan una epistemología inseparable de lo político.

La "herida abierta" que Gloria Anzaldúa identifica con la frontera entre Estados Unidos y México también se palpa en muchos otros países del Caribe y de Latinoamérica como consecuencia de las políticas intervencionistas e imperialistas de Estados Unidos. Aunque no exista una frontera física entre Estados Unidos y las distintas islas del Caribe, la presencia estadounidense en Puerto Rico, Cuba o la República Dominicana es tangible. Y viceversa, pues la inmigración es uno de los efectos directos de la política externa estadounidense:

The U. S.-Mexican border es una herida abierta where the Third World grates against the first and bleeds. And before a scab forms it haemorrhages again, the lifeblood of two worlds merging to form a third country -a border culture. Borders are set up to define the places that are safe and unsafe, to distinguish us from them. A border is a dividing line, a narrow strip along a steep edge. A borderland is a vague and undetermined place created by the emotional residue of an unnatural boundary. It is a constant state of transition. The prohibited and forbidden are its inhabitants. Los atravesados live here (Anzaldúa 1987: 25).

Se ha señalado que a pesar de la diversidad de condiciones históricas y materiales, la comunidad latina comparte la experiencia migratoria a causa del imperialismo de Estados Unidos. "The colonial background is critical to an understanding of the incorporation of various Latino groups in the nineteenth and early twentieth centuries; the migrant experience becomes the basis for comparative understanding of all groups in the twentieth century up to the present" (Sánchez, 2002: 48).

A pesar de ser ciudadanas norteamericanas, las autoras rechazan una asimilación absoluta a la cultura hegemónica, al mismo tiempo que descartan recuperar una idea esencialista de lo que significa ser "mexicana", "cubana" o dominicana". A través de la narrativa emprenden una búsqueda de su propio espacio, un lugar de enunciación que incorpore las contradicciones y ambigüedades de sus experiencias fronterizas. La frontera no remite al límite entre Estados Unidos y México, sino a los intersticios que posibilitan la creación de "a consciousness of the borderlands" (Anzaldúa, 1987: 77) que debe tener en cuenta las condiciones históricas y materiales de los distintos grupos con el fin de impedir generalizaciones o una falsa homogeneización, al tiempo que transciende los marcos nacionales.

En Mestizaje: Critical Uses of Race in Chicano Culture, Rafael Pérez Torres define la frontera como "the interstitial space where differential politics and social dilemmas are negotiated" (2006: 4). La frontera se identifica en este trabajo con un espacio textual donde rearticular una nueva zona de contacto en los intersticios, marcada por las relaciones de poder entre Estados Unidos y los respectivos países de origen de las autoras. Por ello, la metáfora de la frontera se utiliza como espacio desde el que deconstruir y re/construir las narrativas del yo y su representación literaria. El reconocimiento de la realidad material de opresión múltiple que experimentan distintos grupos de mujeres latinas permite 
llevar a cabo un estudio con el objetivo de promover un diálogo que atienda a las ineludibles diferencias que las separan. Por tanto, el análisis de estas obras muestra las ventajas de una perspectiva transnacional, sin que esto implique pasar por alto las especificidades de cada grupo en concreto.

A efectos de este trabajo, la frontera representa un espacio construido textualmente que permite posicionarse en relación a ciertos referentes con el fin de cuestionar y problematizar los ejes sobre los que se apoyan y los intereses a los que responden. La metáfora de la frontera evita esencialismos al identificar la subjetividad como uno de estos espacios construidos $\mathrm{y}$, por ello, susceptibles de ser deconstruidos y re/construidos sobre distintas bases. Sidonie Smith y Watson hacen hincapié en la convergencia con el postmodernismo:

The border is a powerful metaphor in postmodern social analysis. The border tensions of postmodernism as method have blurred boundaries between genres and disciplines, high and popular culture, theory and practice, and a host of binary oppositions — center-periphery, global-local, assimilation-ethnic purity - which validate or authorize restrictive cultural images of social actors, inscribing them in terms of fixed being rather than fluid becoming (1992: 517).

No obstante, mientras que el postmodernismo ha influido en el antiesencialismo, el antifundacionalismo, la deconstrucción y los análisis del discurso llevados a cabo por las autoras, la noción de frontera propuesta en este trabajo parte de un compromiso político basado en la multiculturalidad y la lucha contra cualquier forma de discriminación u opresión por razones de sexo, raza, clase, etnia, sexualidad o nacionalidad. Lejos de limitarse a la deconstrucción, este estudio nace del reconocimiento de la experiencia situada, de la materialidad de cada tiempo y espacio, así como de las circunstancias de cada sujeto y las relaciones de poder específicas que actúan en cada contexto.

A continuación se profundizará en las narrativas del yo con el fin de determinar cómo la experiencia en la frontera contribuye a la creación de un espacio textual en el que se negocian las contradicciones y las ambigüedades que originan una conciencia de la frontera. En segundo lugar se procederá a examinar la manera en que las escritoras juegan con las formas narrativas, adoptando y adaptando géneros para transformarlos en textos híbridos mediante este proceso de revisión. Finalmente, se llevará a cabo un análisis de las implicaciones políticas que se derivan de las narrativas estudiadas. Los "textos fronterizos" no se circunscriben al ámbito de lo literario, sino que por medio de la ficción, las escritoras articulan una epistemología que les lleva formular sus propias teorías en torno a la construcción de subjetividades alternativas, la narración y la política. En otras palabras, de su literatura se desprende una epistemología que puede conectarse con la idea de Anzaldúa y Moraga de que existe una teoría subyacente que parte de la realidad material y discursiva del cuerpo.

La relación de las protagonistas con los distintos espacios que ocupan se caracteriza por lo que Hommi Bhabha denomina "unhomely" (1994) o "displacement" por Bill Ashcroft, quien afirma que "place, and the experience of displacement, emerge out of the interaction of language, history, visual perception, spatiality and environment in the experience of colonized peoples" (2001: 125). Esta experiencia se relaciona con el hecho de vivir "in-between" o, como dice Anzaldúa, "en los intersticios" entre dos culturas, dos lenguas y dos naciones. La subjetividad se forma en un proceso de negociación marcado por la ambivalencia, ya que, tal como se señala en la cita, las protagonistas “come 
to maturity as members of a racial and ethnic minority in a social and historical context in which their political, economic, and cultural uniqueness is constantly undermined, denigrated, and violated" (Segura \& Pierce, 1993: 70). Las mujeres representadas en las obras se ven atrapadas entre dos mundos, discriminadas por la intersección de distintas variables, como la clase, el género, la sexualidad, la nación o la raza. No obstante, las condiciones materiales difieren de unas obras a otras en importantes aspectos que a continuación se detallarán.

The House on Mango Street propone una visión alternativa del género del Bildungsroman y de la subjetividad asociada a éste mediante la representación del proceso de madurez de una adolescente chicana en el barrio latino de Mango Street. La construcción de la subjetividad de Esperanza Cordero se muestra por medio de una serie de viñetas encargadas a su vez de trazar el mapa de Mango Street, con especial atención a la comunidad de mujeres latinas que viven en él. A través de los ojos de la niña, Cisneros reflexiona sobre lo que significa ser mujer en este espacio y contexto social específico. Cada una de las historias de este barrio de las afueras de Chicago contribuye al desarrollo a lo largo de un año de la subjetividad de Esperanza, quien termina por rechazar los roles tradicionales de feminidad preponderantes en la cultura patriarcal chicana, al tiempo que configura narrativamente una nueva subjetividad equiparable en numerosos aspectos a la "nueva mestiza" de Anzaldúa.

Como sugiere el título de la novela, el espacio desempeña un papel central, repercutiendo directamente sobre la identidad de la niña. El relato parte de la experiencia condicionada por una localización que señala la "diferencia", según indican las connotaciones evocadas por el nombre "Mango Street". El yo originado en la narración de Esperanza es inseparable de un esbozo del barrio, que además de situarla contextualmente, pone de manifiesto los lazos que la unen a la colectividad. Condicionada por fuerzas sociales, culturales y también por el espacio, su físico aparece "inflected by race, class, culture, but especially and above all, by space" (Estill, 1994: 40). Estas fuerzas cristalizadas en el cuerpo constituyen fenómenos discursivo-materiales que la posicionan topográficamente, temporalmente y socioculturalmente a través de diversos ejes de significado que contribuyen a su discriminación. El reconocimiento de una subjetividad corpórea o embodied subjectivity conlleva la localización del sujeto en un contexto concreto que, en el caso de la narradora, señala la discriminación múltiple que sufren las mujeres de Mango Street. La alienación de Esperanza ocasiona toda la serie de conflictos que caracterizan su relación con el cuerpo, la casa "the house I belong but do not belong to" (Cisneros, 1991: 109-110), el barrio y la localización "en la frontera".

Durante gran parte de la novela Esperanza expresa su deseo de "a house all my own" (Cisneros, 1991: 108), muy lejos de Mango Street, pero la culminación de su madurez coincide con el descubrimiento final de que la solución no es dar la espalda a sus orígenes, sino revisarlos mediante la escritura: "I put it down on paper and then the ghost does not ache so much. I write it down and Mango says goodbye sometimes. She does not hold me with both arms. She sets me free" (Cisneros, 1991: 110). De esto se desprende que la escritura no se limita a exponer la crítica, sino que también promueve la apertura de nuevos espacios en los que lidiar con las contradicciones y ambigüedades a las que está expuesta como chicana en un barrio de Chicago: "Only a house quiet as snow, a space for myself to 
go, clean as paper before the poem" (Cisneros, 1991: 108). Al igual que Anzaldúa, Esperanza encuentra en la escritura un canal mediante el que negociar con las opresivas condiciones materiales y discursivas hasta culminar, en última instancia, con la proyección de una nueva subjetividad que transforma la ambivalencia en una fuente de creatividad.

En Las historias prohibidas de Marta Veneranda, Sonia Rivera-Valdés se hace eco de diversas voces que conforman un barrio latino en Nueva York. La nota aclaratoria presenta a un personaje ficticio, Marta Veneranda, quien ha recopilado para su tesis doctoral las historias prohibidas de seis mujeres y dos hombres cuyos testimonios constituyen los ocho cuentos de la colección. El libro (colección o novela — dependiendo de la lectura que se haga-) se compone de una polifonía de voces que se dirigen a Marta Veneranda para desvelar "[c]ualquier suceso que para una persona resulta suficientemente vergonzoso como para ser mantenido en secreto (...) su historia prohibida" (RiveraValdés, 2000: 11). Aunque cada relato revela una historia diferente, es posible identificar una serie de temas comunes, como la inmigración, la experiencia de los personajes como minorías dentro de los Estados Unidos o la desestabilización de la identidad por medio de la sexualidad.

En el cuento titulado "El quinto río" se llevan a cabo una serie de reflexiones acerca de la colección y los puntos en común entre los distintos relatos, contribuyendo así a la auto-reflexividad y metaficción del libro: "El hilo conductor de Las historias prohibidas, en el aspecto temático, es la capacidad del ser humano para actuar en un momento determinado de una forma que nunca pensó hacerlo, las sorpresas que una se da a sí misma. Y ante estas situaciones siempre me pregunto, quién es esa una y quién esa si misma" (Rivera-Valdés, 2000: 147). El propósito de cada una de estas narrativas es deconstruir la noción de la identidad como algo fijo y estable. Por el contrario, la subjetividad se concibe como un fluir o proceso configurado mediante la narración, lo que ratifica la idea de que "all people are 'subjects-in-process' and that, to the extent that they are constituted by discourses, they are all multiple and (to some degree) incoherent" (Moya, 2001: 455). "Entre amigas", "Los venenitos" y "Los ojos lindos de Adela" giran en torno a tres víctimas del sistema patriarcal que, en un momento dado, logran subvertir las estructuras que contribuyen a su opresión.

No obstante, en la mayor parte de los casos, el principal elemento desestabilizador es la sexualidad. "La más prohibida de todas" es quizás la historia más transgresora, pues en un giro particularmente subversivo, la narradora Martirio y su amante Rocío reproducen los diálogos sacados de películas eróticas heterosexuales. Paradójicamente, la única relación heterosexual satisfactoria tiene lugar entre Martirio, quien se identifica como lesbiana y Shrinivas, un amante indio que suele acostarse con hombres. A pesar de estar casadas o haberlo estado, tres de las narradoras confiesan sus experiencias sexuales con otras mujeres, lo cual supone un desvío de la heteronormatividad, cuya deconstrucción se ratifica a lo largo de la colección. Es más, tampoco la identidad homosexual se mantiene fija e inalterable, pues en "Desvarios", el narrador homosexual confiesa que el secreto que le atormenta son sus fantasías con mujeres. Tal como apunta la siguiente cita, "la imagen desestabilizadora que predominan en todas estas historias evita las categorizaciones fijas aun de la llamada “identidad homosexual’” (Béjel, 1998: 92). 
La frontera es el tema central que recorre la novela de Alicia Gaspar de Alba, Desert Blood: The Juarez Murders, a través de dos niveles distintos: la subjetividad fronteriza de una narradora queer y chicana y los asesinatos de las mujeres de Juárez. En el prólogo Gaspar de Alba reflexiona acerca del entramado que une lo privado y lo público, lo personal y lo político. Los crímenes sólo pueden entenderse dentro del contexto histórico de estructuras transnacionales de poder: "in the social, political, economic, and cultural infrastructure of the U. S.-Mexico border that makes possible for such crimes to take place with impunity" (Gaspar de Alba, 2005). Si bien es posible estudiar la novela como un intento de sacar a la luz los sucesos de Juárez, este asunto se entrelaza, a su vez, con la historia personal de la protagonista. Ivón es una académica chicana y queer que está escribiendo una tesis en la universidad de Los Ángeles sobre la representación de clase y género en los graffitis de los baños. Cuando ella y su novia deciden adoptar un niño en México, Ivón regresa a su ciudad natal en El Paso, donde descubre con horror los asesinatos de las mujeres de Juárez. La narración proyecta una imagen de la frontera especialmente cruda que no se limita a exponer los crímenes, sino que explora en el contexto en el que estos se producen. De este modo, los cambios sociales y materiales a consecuencia de la industrialización y los procesos de globalización han contribuido a la creación de unas estructuras de poder transnacionales ligadas a lo ocurrido.

Por ahora, no obstante, es conveniente centrarse en cómo el personaje de Ivón permite ahondar en temas como la transgresión que supone el lesbianismo dentro de la tradición mexicana, la complicada relación entre madre e hija o la contradictoria herencia de las nuevas generaciones de chicanas que deben negociar entre los valores tradicionales de la cultura mexicana y la influencia estadounidense. En una de las citas Ivón reflexiona sobre lo siguiente:

Mexican men weren't used to seeing women in men's shorts, not unless they were cholas or lesbians. Either one was bad news in Juárez. As far as Mexicans were concerned, they meant the same thing: traitors. As Americanized Americans spoiled by First World liberties and behaviors, cholas betrayed their own culture. Lesbians, although every macho's wet dream -to voyeurize or to conquer- of course, betrayed not just their culture, but their gender, their families, and their religion (Gaspar de Alba, 2005: 134).

Tal como sugiere Anzaldúa, el lesbianismo no es sólo una elección personal, es también un acto político que reafirma la autonomía femenina al tiempo que conlleva la subversión de los valores patriarcales dentro del contexto chicano. El lesbianismo se asocia con la liberación de las mujeres del "primer mundo", lo cual las identifica con el paradigma de la Malinche. Ivón, sin embargo, funciona como lo que Anzaldúa denomina "border crosser", cuya experiencia a ambos lados de la frontera le impide mantenerse dentro de categorías fijas y estables.

Desde una perspectiva muy diferente Cristina García también explora la repercusión que tienen las relaciones políticas entre Estados Unidos y Cuba en la vida de las mujeres. En su novela Dreaming in Cuban presenta la experiencia de tres generaciones de mujeres de la familia del Pino: la abuela Celia, quien permanece en la isla, su hija Lourdes, empeñada en asimilarse a la cultura estadounidense y Pilar, la nieta a medio camino entre ambos mundos. Lo personal y lo político se entrelazan en la novela de diversas formas. En primer lugar, algunos de los eventos centrales en la vida de las protagonistas coinciden con acontecimientos históricos, como el cumpleaños de Celia y el nacimiento 
de Pilar días después de la entrada de Fidel Castro en La Havana. Asimismo, Celia es defensora del régimen castrista del que Lourdes huye trasladándose a Brooklyn. Pilar es la encargada de mediar entre Celia y Lourdes, entre el pasado cubano y el deseo de asimilación que respectivamente simbolizan. Pilar se rebela contra la memoria procedente de las metanarrativas históricas cuando escribe en su diario: "I resent the hell out of politicians and the generals who force events on us that structure our lives (...) that dictate the memories we'll have when we are old" (García, 1993: 138). Su existencia está condicionada por la experiencia del exilio, lo cual le proporciona un prisma distinto a la hora de abordar el pasado.

Durante su retorno a Cuba, Celia delega en Pilar el deber de recordar. La posición a medio camino entre dos mundos posibilita la construcción de un espacio de enunciación que se asemeja al de la propia autora, quien en una entrevista afirma, "Those of us who kind of straddle both cultures are in a unique postion to tell (...) our family stories. We're still very close to the immigration, and yet we weren't as directly affected by it (...) So we are truly bilingual, truly bicultural" (López, 1993: 612). Al igual que Cristina García, Pilar asume la responsabilidad de inscribir el pasado de su familia, una historia que es invariablemente política. La pintura es el medio que utiliza para representar una memoria que deja en evidencia la subjetividad inherente al acto de recordar. El cuadro de la Estatua de la Libertad o el retrato de su abuela muestran esta doble función de la pintura como una forma de inscribir el pasado en un proceso que inevitablemente lo transforma.

El contexto político de la República Dominicana también determina la vida de las protagonistas de Julia Álvarez. How the Garcia Girls Lost their Accent se compone de quince capítulos que narran el exilio de la familia García en un orden cronológico inverso. Al final se revela que la emigración a Nueva York está motivada por la participación del padre en un intento fallido de la CIA de matar a Trujillo. La novela se centra en el proceso de adaptación de las cuatro hermanas - Yolanda, Sandi, Sofía y Carla-, ahondando en sus sentimientos de desarraigo a consecuencia del desplazamiento. Aunque este argumento resulte familiar, es necesario destacar que la experiencia de las chicas García contrasta con la de Negi o Esperanza, pues a diferencia de estas últimas, las García pertenecen a una clase social privilegiada dentro de la isla. Por lo tanto, si bien la llegada a Nueva York supone un descenso en la escala social y racial, las protagonistas siguen manteniendo muchos de sus privilegios $\mathrm{y}$, de hecho, viajan periódicamente a la República Dominicana, donde conservan su estatus social.

Las hermanas tratan de negociar entre ambos mundos y en el caso de Yolanda, la escritura resultará fundamental a la hora de crear su propio espacio entre las dos culturas. Lejos de asimilarse, Yolanda permanece en la frontera, lo que le proporciona una mirada desde los márgenes con la que deconstruir las narrativas dominantes tanto del país de origen como del de residencia. Al principio de la novela, Yolanda se describe a si misma a través de los ojos de sus familiares en un pasaje que evidencia su rechazo a amoldarse a los modelos de feminidad imperantes entre las mujeres dominicanas pertenecientes a una clase social privilegiada: "Yolanda sees herself as they will, shabby in a black cotton skirt and jersey top, sandals on her feet, her wild black hair held back with a hairband. Like a missionary, her cousins will say, like one of those Peace Corps girls" (2010: 4). La 
reconstrucción de la subjetividad de Yolanda a través de la mirada externa de distintos personajes es un tema que se retoma en la novela $Y o$, donde se explora de nuevo la construcción de una subjetividad marcada por el exilio, el bi/lingüismo y la bi/culturalidad, al tiempo que se da voz a distintos personajes que proporcionan una visión de la República Dominicana desde múltiples perspectivas. Álvarez utiliza la ficción para acercar la historia de su país al público americano, además de presentar individuos que negocian entre dos mundos. En relación con esto, es interesante mencionar cómo el traslado de un país a otro conlleva una transposición de las categorías y de los sistemas de valores que configuran la realidad.

Un caso especialmente notable es que en Estados Unidos las hermanas García toman conciencia de su raza, pasando de estar en lo más alto de la escala racial en la República Dominicana a formar parte de una minoría en Estados Unidos: "This shift in classification itself reveals the relativity of social groupings, thereby reinforcing the fictive nature. If two countries can construct these categories differently, where in one a Spanish ancestry is racialized and in another is not. We must consider how these categories are socially rather than biologically created or natural" (Quintana, 2003: 19). La materialidad del cuerpo en general, y en especial del cuerpo estigmatizado por la intersección de la discriminación múltiple tiene una historia que lo equipara a un texto cultural. Las dos novelas de Álvarez desmantelan el espejismo de que hay una correspondencia entre la biología y las categorías socioculturales como la raza. En este sentido, la representación del cuerpo se asemeja a la visión de Elisabeth Grosz, quien rechaza que se trate de "an ahistorical, biologically given, acultural object" (1994: 18).

La construcción de la subjetividad de las protagonistas revela la confluencia de los discursos y condiciones materiales que actúan sobre el cuerpo entendido como espacio geopolítico y sociosimbólico, como una materialidad codificada y representada en el lenguaje. Aunque se ha demostrado que el contexto de cada una de las autoras es diferente, todas ellas comparten una preocupación por la doble exclusión que afecta a las protagonistas como mujeres y como minorías. En Borderlands/ La Frontera Gloria Anzaldúa profundiza en esta doble discriminación al explicar que "[a]lienated from her mother culture, 'alien' in the dominant culture, the woman of color does not feel safe within the inner life of her Self' (1987: 42). La interacción de los fenómenos materiales y discursivos contribuyen al sentimiento de alienación que Esperanza, las hermanas García, Pilar y Lourdes, las distintas voces que entrevista Marta Veneranda y Negi manifiestan hacia su cuerpo, ilustrando la constatación de Sidonie Smith de que "the body is our most material site of potential homelessness" (1993: 267).

La narración sitúa a las protagonistas en relación con su contexto, experimentando algo similar a lo que Anzaldúa llama "a struggle of flesh, a struggle of borders, an inner war" (1987: 100). Paradójicamente, la representación de esta ambivalencia sirve de base para la articulación de una crítica mediante la que proyectar formas de resistencia. Siguiendo la observación de Anzaldúa, "The possibilities are numerous once we decide to act and not react" (1987: 101). La escritura y la pintura, en el caso de Pilar, proporcionan las herramientas con las que transformar sus destinos. De ellas emerge 


\section{Tropelías. Revista de Teoría de la Literatura y Literatura Comparada, 29 (2018)}

La frontera como zona de contacto transnacional en la literatura latina estadounidense

una revisión y redefinición de la subjetividad que lejos de concebirse como una esencia fija y estable, constituye un fluir, un "devenir" que les permite aceptar las contradicciones y ambigüedades. Las obras abrazan el bi/lingüismo, la "bi/culturalidad" y la construcción narrativa de un espacio de enunciación desde la frontera entre los distintos mundos, ideologías y lenguas. Las protagonistas crean una subjetividad que se asemeja a lo que Anzaldúa denomina "a consciousness of the borderlands" (1987: 77) o la nueva mestiza. No es casual que el proceso de madurez de Esperanza, Pilar, Negi, o las hermanas García culmine con el reconocimiento de esta tercera posibilidad, "developing a tolerance for contradictions, a tolerance for ambiguity (...) Not only does she sustain contradictions, she turns the ambivalence into something else" (Anzaldúa, 1987: 101). Al igual que Anzaldúa, las protagonistas encuentran en la escritura y la pintura un canal mediante el que negociar con las opresivas condiciones materiales y discursivas hasta promover, en última instancia, la creación de voces desde la frontera.

La teoría de Gloria Anzaldúa se despliega por medio de un texto híbrido en el que confluyen la poesía, el ensayo, la teoría política, la crítica social, la historia, la mitología, así como fragmentos pertenecientes a la cultura popular. La construcción de un tercer espacio desde el que revisar y re/articular la subjetividad de la frontera corre pareja a la búsqueda de formas de expresión adecuadas a la representación de su realidad más inmediata. En este sentido, los textos seleccionados pueden interpretarse como distintas respuestas a las preguntas que Madsen formula acerca del siguiente dilema:

[...] how to speak from a discredited cultural position; how to write when established literary forms have been devised to express the lives and thoughts of men (colored and white) and white women. Chicana writers have responded to these problems by seeking to construct or reconstruct ethnic women's literary traditions ( ...) These writers subvert conventional forms of literary expressions to make them express colored women’s experiences (2000: 4).

Gloria Anzaldúa, Sandra Cisneros, Julia Álvarez, Cristina García, Alicia Gaspar de Alba y Sonia Rivera-Valdés proponen una conciencia de la frontera sirviéndose de textos híbridos que difieren de las representaciones convencionales. El objetivo de su búsqueda es hallar una voz o canal de expresión con el que relatar la experiencia de mujeres latinas pertenecientes a distintos grupos. Las herramientas literarias o "master's tools" se utilizan con fines subversivos que les permiten deconstruir "the master's house" y re/construir un hogar alternativo. "I will have to stand and claim my space, making a new culture - una cultura mestiza - with my own lumber, my own bricks and mortar and my own feminist architecture" (Anzaldúa, 1987: 22)

Esta búsqueda es el punto de partida de Marta Veneranda. En la nota aclaratoria de Las historias prohibidas se explica que la recopilación de Marta Veneranda surge en un principio por la iniciativa de su profesor Arnold Haley, quien la anima a que investigue etnográficamente lo que distintas personas consideran vergonzoso. A medida que Marta Veneranda comienza a interaccionar con la gente del barrio se da cuenta de que los cuestionarios no hacen justicia a la complejidad de las experiencias humanas. En un acto sumamente subversivo rechaza los métodos científicos positivistas

\footnotetext{
${ }^{1}$ En referencia al famoso ensayo de Audre Lorde “The Master's Tools Will Never Dismantle the Master's House” (1984).
} 
para terminar escribiendo una tesis en literatura, en contra de los consejos de su profesor, representante del discurso científico: "El doctor Haley insistió en la necesidad de rigor científico. Desgraciadamente, nuestras desavenencias profesionales aumentaron (...) al término de cada grabación, la transcripción me proporcionaba un nuevo cuento, de cuya fascinación no podía sustraerme, en lugar de ante una serie de datos cuantificables" (Rivera-Valdés, 2000: 6). A través de este acto, Marta Veneranda reafirma su autonomía, así como la de sus interlocutores, quienes se construyen como sujetos por medio de su narrativa, en lugar de objetos del estudio etnográfico.

Las autoras comparten su resistencia a la hora de ceñirse a las convenciones, proponiendo en su lugar textos fundamentalmente híbridos. De este modo se realiza lo que Norma Alarcón ha denominado "revisionary dialogue" con las formas tradicionales de representación literaria. Por ejemplo, Sandra Cisneros lleva a cabo la revisión y redefinición del género del Bildungsroman a través de la representación de la experiencia de una adolescente chicana. Pedro Gutiérrez Revuelta en "Género e Ideología en The House on Mango Street" considera que The House on Mango Street constituye "un género nuevo" (1986: 49), influido por el postmodernismo, el postcolonialismo y, sobre todo, el feminismo de la frontera. Las novelas de Julia Álvarez también se centran en el desarrollo de Yolanda García como escritora con la peculiaridad de que este yo se reconstruye a través de una polifonía de voces. Asimismo, The House on Mango Street y Las historias prohibidas de Marta Veneranda se componen de un conjunto de relatos que pueden leerse por separado o en conjunto con el resto como si fueran piezas de un puzzle imposible de completar en su totalidad. Ellen McCracken se refiere a la obra de Cisneros como "a collection" (1989: 63) de cuarenta y cuatro viñetas que ofrecen imágenes fragmentadas del barrio. Con una idea similar Renato Rosaldo atribuye a los ciclos de relatos las siguientes características que son a su vez aplicables a The House y a Las historias prohibidas: "the formal marginality of short story cycles enables them to become arenas for experimentation, the development of alternative visions [...] Marginal genres thus are often the site of political innovation and cultural creativity" (1988: 88). En cuanto a Desert Blood, Gaspar de Alba reinventa el género policiaco al atribuirle a su protagonista queer y chicana el papel de detective.

En otras palabras, la apertura de un espacio desde el que articular subjetividades fronterizas va acompañada de una experimentación en el plano de lo formal. La reflexión en torno al proceso de escritura o de creación artística en el caso de Pilar contribuye a la auto-reflexividad y la metaficción de los textos, mostrando que en estos casos la forma concuerda con el contenido. En lugar de amoldarse a las convenciones de un género literario en concreto, las autoras recurren a un hibridismo a nivel formal que es representativo del hibridismo de las subjetividades teorizadas. En oposición a las visiones totalizadoras o unificadoras, estos "textos fronterizos" pueden conectarse con la definición de Victor Turner de "liminality" como "a fructile chaos, a fertile nothingness, a storehouse of possibilities, not by any means a random assemblage but a striving after new forms and structure" (1985: 295). No es casual que todos estos textos rompan con el orden cronológico, ya que en vez de una narrativa lineal y coherente, se hace uso de una lógica asociativa que evidencia una subjetividad experimentada de 


\section{Tropelías. Revista de Teoría de la Literatura y Literatura Comparada, 29 (2018)}

La frontera como zona de contacto transnacional en la literatura latina estadounidense

forma fragmentaria. La discontinuidad, por consiguiente, impide que se transmita una falsa impresión de coherencia o unidad.

Otra de las características formales que impera en la mayoría de textos es la polifonía de voces, que puede interpretarse como un intento de establecer una reciprocidad entre el individuo y la colectividad. Las narrativas de Cisneros, Gaspar de Alba, Julia Álvarez, Cristinas García, Sonia Rivera-Valdés y, por supuesto, Anzaldúa se oponen al individualismo de la tradición occidental. En este sentido, la subjetividad de las protagonistas se asemeja a la idea de Beverley de la configuración del "yo en un modo colectivo" (2004: 17) ${ }^{2}$. Esta representación del yo en modo colectivo otorga valor representacional y especificidad a la comunidad de mujeres en la que se integran. En Borderlands/La Frontera, Anzaldúa conecta la memoria personal a un contexto de lucha política. El reconocimiento del importante papel de la narración como proyecto artístico y político sobre el que fundar una epistemología o "theory in the flesh" es uno de los puntos en común entre el feminismo de color y el feminismo de la frontera.

La exhibición de subjetividades y modos de representación que contrastan con los modelos hegemónicos tiene el efecto de visibilizar colectivos excluidos de los discursos dominantes, con las repercusiones que esto comporta a nivel político. Tal como señala la siguiente cita, "self-construction depends upon creating new spaces between languages, cultures, and places that are impossible to regain or achieve, and the present accommodation, which transforms the place of transformation. The liminal spaces present creative, highly politicized opportunities for self-construction in mirror talk" (Egan, 1999: 27). La ficción de Cisneros, Álvarez, García, Rivera-Valdés y Gaspar de Alba indaga en los complejos lazos que vinculan la narración, la memoria y la política, materializando el alegato de que lo personal es político.

La representación del mundo desde puntos de vista tradicionalmente silenciados otorga especificidad a ciertos sectores y esto a su vez contribuye a su "empoderamiento". En el caso de Álvarez, es posible identificar una transición desde los conflictos personales asociados a la inmigración a la representación de la situación histórica de la República Dominicana. La política inherente al acto de narrar también se refleja en The House on Mango Street a través de las Comadres que se hacen eco del deber moral de Esperanza de dar voz a sus recuerdos: "When you leave you must remember to come back for the others. A circle, understand? You will always be Esperanza. You will always be Mango Street. You can't erase what you know: You can't forget who you are" (Cisneros, 1991: 105). En The House Esperanza regresa de manera simbólica al barrio con el objetivo de transformarlo valiéndose de la imaginación. La novela representa el imperativo de recordar, lo que implica un retorno imaginario al barrio y, más concretamente, a la comunidad de mujeres que lo pueblan. Las responsbilidad políticas de las protagonistas se canaliza en todos estos casos hacia la narración.

\footnotetext{
${ }^{2}$ La conexión entre individuo y colectividad es un elemento central en la definición de Beverley de testimonio: "Testimonio represents an affirmation of the individual subject, even of individual growth and transformation, but in connection with a group or class situation marked by marginalization, oppression, and struggle. If it looses that connection it ceases to be testimonio" (36).
} 
La aparición de las tres comadres señala, asimismo, el valor de la narración para dar voz a experiencias silenciadas. La visibilización de las historias del barrio por medio de la escritura se refleja también en Las historias prohibidas, donde la narración realiza una importante función política al cuestionar las categorías normativas, ofreciendo formas de ser y actuar más flexibles y liberadoras. Como indica Julia Watson: "The project of naming the unspeakable is an effort to pose the problem of the relationship between personal experience and political goals as an instrument for change" (1998: 400). En el caso de Cristina García, los cuadros de Pilar pueden considerarse representativos del poder del arte como medio para inscribir el pasado a partir de una memoria subjetiva, no del todo fiable, pero que, sin embargo, le proporciona una genealogía. Según O’Reilly Herrera, Pilar demuestra que "her hybrid status, coupled with her use of painting as a way of transforming private and public knowledge and the history that Celia wants her to guard, allows her to creatively fill the void of history that was replaced by imagination" (1995: 89).

En Desert Blood Gaspar de Alba reflexiona acerca de la necesidad de romper el silencio que rodea los asesinatos de Juárez. Su novela visibiliza y denuncia la explotación de las maquiladoras y sus asesinatos, al tiempo que contribuye a la comprensión del contexto. "The maquiladora is a site where multiple forms of both local and global oppression come together" (Mata 2010: 22). La explotación económica de las mujeres en la frontera pasa a un primer plano a lo largo de la novela, sacando a la luz las estructuras sociales que han hecho posible que se cometan estos actos sin ningún tipo de impunidad. Gaspar de Alba emplea un análisis que tiene en cuenta la industrialización de Juárez, así como los procesos de globalización que han alterado las circunstancias de las mujeres de la frontera. La tesis doctoral que Ivón escribe le permite llevar a cabo toda una serie de hipótesis e investigaciones en torno al contexto en que se enmarcan los asesinatos. Al igual que en Las historias prohibidas, la tesis doctoral no se limita a un estudio académico, sino que cumple una función política de visibilización y de denuncia, plasmando la repercusión de la epistemología producida en el ámbito académico.

Las protagonistas recurren a la creación artística y a la escritura académica en el caso de Marta Veneranda e Ivón con el fin de visibilizar experiencias y colectivos tradicionalmente silenciados. Al dar voz a grupos excluidos de los discursos sociales dominantes en los Estados Unidos, las autoras contribuyen a restituir la especificidad y singularidad de los distintos colectivos de mujeres latinas. Es más, a través de las narrativas las autoras construyen su propia epistemología, una teoría que emerge del conocimiento situado, de las condiciones materiales y discursivas del cuerpo, llevando a cabo lo que Moraga y Anzaldúa han denominado "theory in the flesh”. Este hincapié en la teoría anclada en el cuerpo como espacio epistemológico no puede obviar las diferencias de las condiciones materiales y discursivas que afectan a las diversas mujeres. El diálogo entre estas obras traslada las relaciones de poder a un primer plano. El contraste entre las novelas de Julia Álvarez y otros libros como The House on Mango Street permite reflexionar acerca de la clase social como un factor central a tener en cuenta. También en Dreaming in Cuban se encuentran varios ejemplos acerca de cómo los "latinos" distan mucho de poder considerarse un grupo homogéneo. Por ejemplo, el éxito de las pastelerías de Lourdes 
se debe en parte a la explotación de inmigrantes ilegales, entre ellas una mujer puertorriqueña. También Pilar destaca que su situación económica difiere de la de su novio chicano, Max, cuya única familia es su madre, quien subsiste limpiando casas.

También la raza adquiere mayor relevancia en algunos textos como el de Cisneros o Santiago que en otros, como los de Rivera-Valdés y García. Finalmente, la lengua constituye otra diferencia importante. Mientras Las historias prohibidas están escritas en español, las demás autoras optan por el inglés. Sin embargo, la influencia del español se hace sentir en nombres, referencias culturales o expresiones. En la introducción de Women's Voices from the Borderlands, Lillian Castillo-Speed observa que "It is more than just a combination of English and Spanish: it reflects the reality of women who live in two worlds" (1995: 18). Finalmente, las relaciones políticas entre los Estados Unidos y los países de origen de las autoras tampoco deben dejarse de lado, pues los factores políticos, sociales, económicos y raciales repercuten en las preocupaciones y representaciones fronterizas de las autoras. Por ejemplo, Cisneros, Santiago y Rivera-Valdés muestran mayor interés en la vida de los barrios de grupos discriminados, mientras que García, Cisneros y Gaspar de Alba inciden más en la situación política de su país.

A pesar de sus innegables diferencias, el estudio de estas obras permite establecer diálogos transnacionales mediante los que dar voz a las distintas experiencias de mujeres latinas sin eclipsar sus diferencias. El análisis de estos textos puede leerse como el intento de establecer una zona de contacto en los intersticios que, tal como Bhabha afirma, proporcionan los espacios desde los que contestar las narrativas imperialistas y globalizadoras. Según indica Sonia Saldívar-Hull, "[t]he written word, then, becomes essential for communication when face-to-face contact is not possible. Particularly for so many Latinas who can no longer claim our country, or even the domain of our homes- barely holding la tierra below our feet- we need a literature that testifies to our lives" (2000: 47). La poética, la (est)ética y la política atraviesan el proyecto de estas autoras, cuyo objetivo último es dar testimonio de vidas y experiencias que exigen ser narradas y escuchadas.

\section{Referencias bibliográficas}

ÁlvarEZ, J. (1997): Yo. Chapel Hill, Alconquin Books. (2010): How the García Girls Lost their Accents. Chapel Hill, Alconquin Books.

AnZALdúA, G. (1987): Borderlands/La Frontera: The New Mestiza. San Francisco, Aunt Lute Books. ASHCROFT, B. (2001): Post-Colonial Transformation. London, Routledge.

BнAвHA, H. (1994): The Location of Culture. London, Routledge.

BÉJEL, E. (1998): “Las historias prohibidas de Marta Veneranda: una estética de la desestabilización”, Confluencia, 14, pp. 87-99.

BeVERLY, J. (2004): Testimonio: On the Politics of Truth. Minneapolis, University of Minnesota Press. CASTILLO-SPEED, L. (1995): Women's Voices from the Borderlands. New York, Simon \&Schuster. Cisneros, S. (1991): The House on Mango Street. New York, Vintage Contemporaries. 
416 Tropelías. Revista de Teoría de la Literatura y Literatura Comparada, 29 (2018)

Macarena García-Avello

Egan, S. (1999): Mirror Talk: Genres of Crisis in Contemporary Autobiography. Chapel Hill, University of North Carolina Press.

EstiLl, A. (1994): "Building the Chicana Body in Sandra Cisneros's My Wicked Wicked Ways", Rocky Mountain Review of Language and Literature, 56, pp. 25-43.

García, C. (1993): Dreaming in Cuban. New York, Ballantine Books.

Gaspar de AlbA, A. (2005): Desert Blood: The Juarez Murders. Houston, Arte Público.

Grosz, E. (1994): Volatile Bodies. Toward a Corporeal Feminism. Bloomington, Indiana University Press.

Gutiérrez Revuelta, P. (1986): “Género e Ideología en The House on Mango Street”, Crítica, 1/3, pp. 48-59.

LÓPEZ, I. H. (1993): ““ ...And There Is Only Imagination where Our History Should Be’: An Interview with Cristina Garcia", Michigan Quarterly Review; en http://hdl.handle.net/2027/spo.act2080. 0033.003:27 (última consulta, 1-1-2018).

Madsen, D. (2000): Understanding Contemporary Chicana Literature. Columbia, University of South Carolina Press.

MATA, I. (2010): "Writing on the Walls: Deciphering Violence and Industrialization in Alicia Gaspar de Alba's Deser Blood”, MELUS: Multi-Ethnic Literature of the U. S., 35, pp. 15-40.

MCCracken, E. (1989): "Sandra Cisneros' The House on Mango Street: Community- Oriented Introspection and Demystification of Patriarchal Violence", en Asunción HORNO-DELGADO et al., eds., Breaking Boundaries: Latina Writings and Critical Readings. Amherst, University of Massachussetts, pp. 62-71.

MoyA, P. (2001): “Chicana Feminism and Postmodernist Theory”, Signs, 26/2, pp. 441-483.

O’ReIlly HerrerA, A. (1995): "Women and the Revolution in Cristina Garcia's Dreaming in Cuban", Modern Language Studies, 27.3/4, pp. 70-91.

PÉrez TORRes, R. (2006): Mestizaje: Critical Uses of Race in Chicano Culture. Minneapolis, University of Minnesota Press.

QuintanA, A. (2003): Reading U. S. Latina writers: Remapping American Literature. New York, Palgrave Macmillan.

RANCIÈRE, J. (2004): “The Politics of Literature", en https://www.colorado.edu/humanities/ferris/ Courses/1968/Ranciere/Texts/Ranciere_Politics\%20of\%20Literature_SubStance103_33.1_200 4.pdf (última consulta, 1-1-2018).

RIVERA-VALDÉS, S. (2000): Las historias prohibidas de Marta Veneranda. New York, Seven Stories Press.

Rosaldo, R. (1988): Fables of the Fallen Guy. Stanford, Stanford University Chicano Research Center.

Saldivar-Hull, S. (2000): Feminism on the Border: Chicana Gender Politics Literature. Berkeley, University of California Press. 
SÁncheZ, G. (2002): “Y Tú, Qué?”, en Marcelo M. SuÁreZ-OrozCo y Marcela M. PÁEZ, eds., Latinos Remaking America. Berkeley: University of California Press, pp. 45-58.

SegurA, D. - Pierce, J. (1993): “Chicana/o Family Structure and Gender Personality: Chodorow, Familism, and Psychoanalytic Sociology Revisited”, Signs, 19/1, pp. 62-91.

SMITH S. (1993): Subjectivity, Identity, and the Body: Women's autobiographical practices in the twentieth century. Bloomington, Indiana University Press.

Smith, S. - Watson, J. (1992): Delcolonizing the subject: The politics of gender in women's autobiography. Minneapolis, University of Minnesota Press.

Socolovsky, M. (2013): Troubling Nationhood in U. S. Latina Literature. Explorations of Place and Belonging. New Brunswick, Rutgers University Press.

TuRner, V. (1985): On the Edge of the Bush: Anthropology as Experience. Tucson, University of Arizona Press.

Watson, J. (1998): “Unspeakable Differences: The Politics of Gender in Lesbian and Heterosexual Women's Autobiographies", en Sidonie SMith y Julia Watson, eds., Women, Autobiography, Theory: A Reader. Madison, The University of Wisconsin Press, pp. 393-402.

YARbro-Bejarano, Y. (1994): “Gloria Anzaldúa's Borderlands / La frontera: Cultural Studies, "Difference", and the Non-Unitary Subject", Cultural Critique, 17/4, pp. 5-35. 